\title{
Low Frequency Wireless Power Transfer using Optimal Primary Capacitance of Parallel Resonance for Impedance Matching
}

\author{
Artit Rittiplang $^{1}$ and Wanchai Pijitrojana ${ }^{1}$ \\ Electrical and Computer Engineering Dept., Faculty of Engineering, Thammasat University, Pathumthani, Thailand ${ }^{1}$
}

\begin{abstract}
Wireless Power Transfer (WPT) has been widely studied for decades by using the Series Resonance (SR). Most of the resonant frequency is in a range of $200 \mathrm{kHz}-13.56 \mathrm{MHz}$. Additionally, a pure resistive load is commonly adopted for simplifying a design under Impedance Matching (IM) condition. However, there are usual problems presented in the past studies. For example, i) common electrical loads are complex, so the SR structures are difficult to be designed for achieving the IM condition, ii) the resonant frequency in this range causes several problems, e.g. the tissue absorption on humans, electromagnetic interference, etc. In this paper, we propose the method to design the Parallel Resonance (PR) using an optimal primary capacitance for achieving the IM condition, which can operate at a low frequency, as $15 \mathrm{kHz}$, at a complex load.
\end{abstract}

Keywords: Low frequency wireless power transfer, low resonant frequency, parallel resonance, impedance matching, wireless power transfer.

\section{INTRODUCTION}

WPT based on magnetic resonant coupling have been widely investigated in recent years according to the schematic diagram as shown in Fig. 1 [1]-[19].

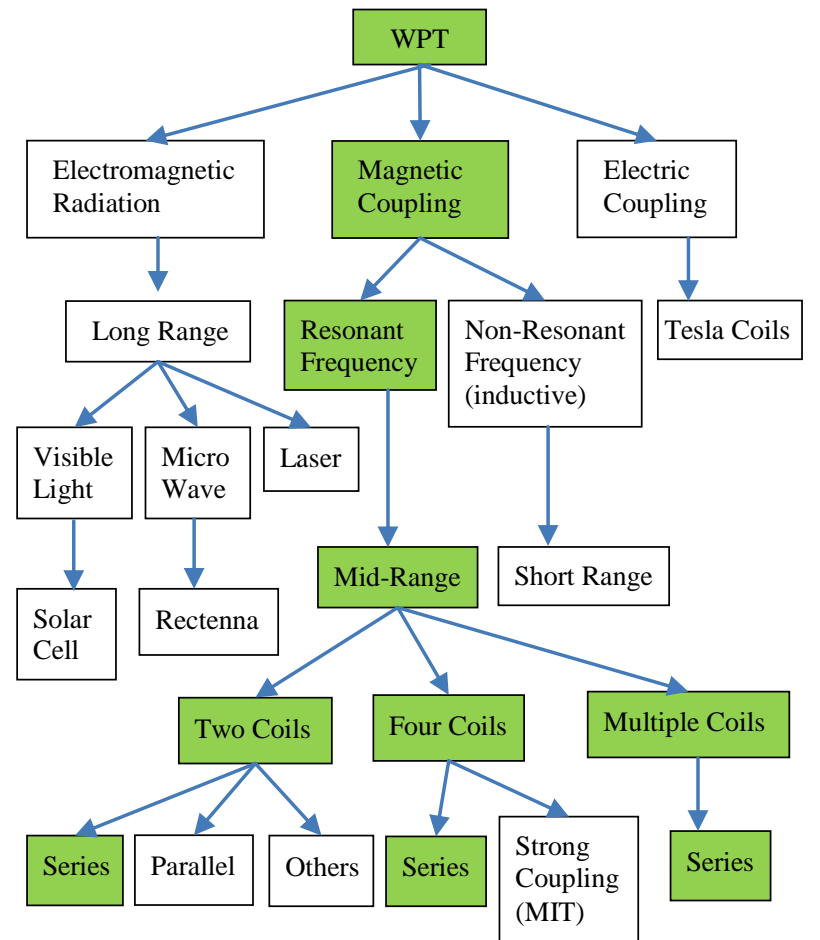

2) The frequency operation in this range causes several problems such as the parasitic losses in the circuit, tissue absorption on humans, electromagnetic interference, most inefficient power sources, etc [1], [13]-[17]. Also, these structures are difficult to design for operating the frequency of less than $100 \mathrm{kHz}$ by using air core, while maintaining the high efficiency [1]. In [13], we proposed the PR structure as shown in Fig. 2, which can operate at $f_{0}$ less than $40 \mathrm{kHz}$ (low frequency radio band [1], [13]). But the IM condition cannot be achieved in case of a complex load.

To improve the above problems, this paper presents the method to find an optimal primary capacitance of the PR structure. As a result, the system can operate at low frequency $(f) 15 \mathrm{kHz}$ while satisfying the IM condition under a complex load.

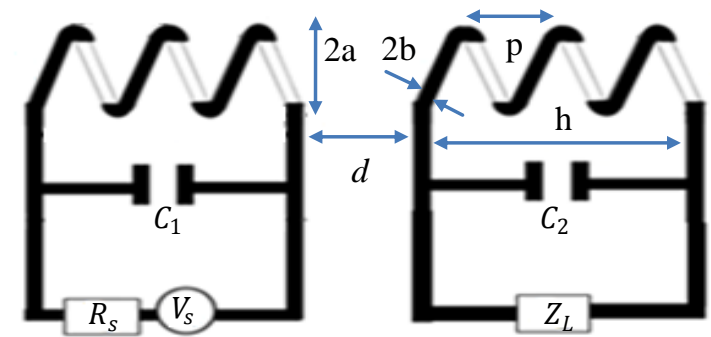

Fig. 2. Typical diagram of PR structure.

Fig.1. the most common WPT can be mainly categorized into three types.

A two-coil, a four-coil, and a multiple-coil SR structures have been widely studied by using the resonant frequency $\left(f_{0}=1 / 2 \pi \sqrt{\mathrm{LCC}}\right)$ in a range of $200 \mathrm{kHz}-13.56 \mathrm{MHz}$ [2]-[11]. However, there are common problems as follows:

1) These structures are difficult to be implemented in case of a complex load for achieving the IM condition when the secondary capacitor and coil are fabricated.

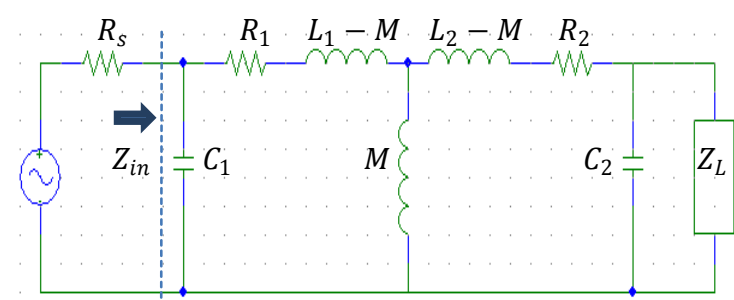

Fig. 3. Equivalent circuit of Fig. 2. 


\section{THEORY}

From Fig. 3, to maximize the input power (IM condition), the input impedance must be equal to a source impedance $\left(R_{s}=Z_{i n}\right)$ [1]-[9]. In [13], we presented the PR structure under the IM condition by using mutual inductance $(M)$ as shown in (5). However, the IM condition cannot be achieved in case of a complex load at $f_{0}$ because the imaginary part of the input impedance is not equal to zero $\left(X_{i n}\left(f_{0}\right) \neq 0\right)[18]$.

To satisfy the IM condition at a complex load, we determine $C_{l}$ to obtain $X_{i n}\left(C_{l}\right)=0$ as shown in (2) at the frequency range as shown in (1).

$\sim 1.2 \frac{\sqrt{R_{s} R_{d c 1}}}{2 \pi L_{1}}<f<\sim 3.4 \frac{\sqrt{R_{s} R_{d c 1}}}{2 \pi L_{1}}$

From (1), we can find a low $f$ by determining the high value of $L_{l}$. Where $R_{d c l}$ is a DC resistance of the sending coil, as well as $R_{s}$ and $R_{L}$ in the system are set to be greater than $10 \mathrm{ohm}$.

$X_{\text {in }}\left(C_{1}\right)=\omega\left(\alpha^{2}+\beta^{2}\right) C_{1}-\beta=0$

Where,

$$
\begin{aligned}
& \alpha=R_{1}+\frac{\omega^{2} M^{2}\left(R_{2}+B\right)}{A} \\
& \beta=\omega L_{1}-\frac{\omega^{2} M^{2}\left(\omega L_{2}-\omega C_{2} R_{L} B+\frac{\left(X_{L}-\omega C_{2} X_{L}^{2}\right) B}{R_{L}}\right)}{A}
\end{aligned}
$$

$$
M=\frac{\sqrt{A}}{\omega} \sqrt{\frac{L_{1}-C_{1} R_{S} R_{1}}{L_{2}+C_{1} R_{S} R_{2}+C_{1} R_{S} B-C_{2} R_{L} B+\frac{\left(X_{L}-\omega C_{2} X_{L}^{2}\right) B}{\omega R_{L}}}}
$$

(3) Where

$$
A=\left(R_{2}+B\right)^{2}+\left(\omega L_{2}-\omega C_{2} R_{L} B+\frac{\left(X_{L}-\omega C_{2} X_{L}^{2}\right) B}{R_{L}}\right)^{2}
$$$$
B=\frac{R_{L}}{\left(1-\omega C_{2} X_{L}\right)^{2}+\omega^{2} C_{2}^{2} R_{L}^{2}}
$$

$C_{2}=\frac{1}{L_{2} \omega^{2}}$

(6)

(7) assumed to be an inductive load with a resistance and an

We apply the command "solve" from MATLAB program for solving (2) to get several $C_{l}$. Next, we are able to compute $M$ from (5), with which an optimal $C_{l}$ is selected to make both $L_{1}-M$ and $L_{2}-M$ are greater than zero.

\section{III.ELECTRICAL PARAMETERS}

From Fig. 2, parameters of coil size; a, b, p, h, and $\mathrm{N}$ are the loop radius, the wire radius, the pitch, the height, and a number of turns, respectively, where $d$ is the transfer distance. The parameters of coil size are calculated for obtaining the resistance $R_{1}$ and $R_{2}$ and the self-inductance $L_{1}$ and $L_{2}$ of Fig. 3 .

1). $R_{1}$ and $R_{2}$ can be calculated from (9) [18]

$$
R=\frac{R_{d c} \mathrm{~b}^{2}}{\delta\left(1-e^{-\frac{\mathrm{b}}{\delta}}\right)\left(2 \mathrm{~b}-\delta\left(1-e^{-\frac{\mathrm{b}}{\delta}}\right)\right)}
$$

As shown in Fig. 2, we set the radii, a, of sending and receiving coils to be $9 \mathrm{~cm}$ and $6.2 \mathrm{~cm}$, respectively. There are $\mathrm{N}=10$ turns, $\mathrm{b}=0.5 \mathrm{~mm}, \mathrm{p}=1.1 \mathrm{~mm}, \mathrm{~h}=12 \mathrm{~mm}$. The power source is set as $10 \mathrm{~V}$ at $R_{s}=50 \Omega$. The load is inductance $15 \Omega$ and $100 \mu \mathrm{H}$, respectively. We compute $R_{\mathrm{DC}}$ and $L$ as shown on the left column of Table I. We

where

$$
R_{d c}=\frac{\rho l}{\pi \mathrm{b}^{2}} \text { and } \delta=\sqrt{\frac{\rho}{\pi \mu_{0} f}}
$$

$R_{d c}$ is the DC resistance, $\rho$ is the resistivity of copper $\left(1.68 \times 10^{-8} \Omega . \mathrm{m}\right), \mu_{0}$ is the permeability $\left(4 \pi \times 10^{-7} \mathrm{H} \cdot \mathrm{m}^{-1}\right), l$ is the length of the conductor, and $\delta$ is the skin depth.

2). $L_{1}$ and $L_{2}$ are obtained as shown in (11) [2]

$L=\frac{\mu_{0} \pi(2 \mathrm{a})^{2} \mathrm{~N}^{2}}{4 \mathrm{~h}} k_{L}-\mu_{0} \mathrm{aN}\left(k_{s}+k_{m}\right)$

Where,

$$
k_{L} \approx \frac{\mathrm{h}}{\pi \mathrm{a}}\left[\frac{\left(\ln \left(\frac{8 \mathrm{a}}{\mathrm{h}}\right)-0.5\right)}{1+0.258952\left(\frac{\mathrm{h}}{2 \mathrm{a}}\right)^{2}}\right]
$$

$k_{s} \approx \frac{3}{2}-\ln \left(\frac{\mathrm{p}}{\mathrm{b}}\right)$ and $k_{m} \approx \ln (2 \pi)-\frac{3}{2}-\frac{\ln (\mathrm{N})}{6 \mathrm{~N}}$

The efficiency $(\eta)$ of Fig. 3 can be calculated using twoport network in the form of $Z$ matrix as shown in (14) [19].

$\eta=\frac{\operatorname{Re}\left\{Z_{L}\right\}}{\operatorname{Re}\left\{Z_{\text {in }}\right\}}\left|\frac{Z_{21}}{Z_{22}+Z_{L}}\right|^{2} * 100$

$$
\begin{aligned}
& {\left[\begin{array}{ll}
Z_{11} & Z_{12} \\
Z_{21} & Z_{22}
\end{array}\right]=\left[\begin{array}{ll}
\frac{A_{a}}{C_{c}} & \frac{A_{a} D_{d}-B_{b} C_{c}}{C_{c}} \\
\frac{1}{C_{c}} & \frac{D_{d}}{C_{c}}
\end{array}\right] } \\
& {\left[\begin{array}{ll}
A_{a} & B_{b} \\
C_{c} & D_{d}
\end{array}\right]=\left[\begin{array}{cc}
1 & 0 \\
j \omega C_{1} & 1
\end{array}\right]\left[\begin{array}{cc}
1 & R_{1}+j \omega L_{1} \\
0 & 1
\end{array}\right] \ldots } \\
& {\left[\begin{array}{cc}
0 & -j \omega M \\
\frac{-j}{\omega M} & 0
\end{array}\right]\left[\begin{array}{cc}
1 & R_{2}+j \omega L_{2} \\
0 & 1
\end{array}\right]\left[\begin{array}{cc}
1 & 0 \\
j \omega C_{2} & 1
\end{array}\right] }
\end{aligned}
$$

obtain a range of the frequency using (1), i.e. $10 \mathrm{kHz}<f<$ $30 \mathrm{kHz}$.

\section{TABLE I: DESIGN ELECTRICAL PARAMETERS}

\begin{tabular}{|c|c|c|c|}
\hline Parameter & VALUE & Parameter & VALUE \\
\hline$L_{1}(\mathrm{H})$ & $39.461 \mu$ & $C_{2}(\mathrm{~F})$ & $4.642 \mu$ \\
\hline$L_{2}(\mathrm{H})$ & $24.252 \mu$ & $Z_{L}(\Omega)$ & $15+j 9.4248$ \\
\hline$R_{\mathrm{DC}}(\Omega)$ & $102 \mathrm{~m}$ & $R_{1}(\Omega)$ & $138 \mathrm{~m}$ \\
\hline$R_{\mathrm{DC} 2}(\Omega)$ & $70 \mathrm{~m}$ & $R_{2}(\Omega)$ & $95.1 \mathrm{~m}$ \\
\hline$R_{s}(\Omega)$ & 50 & & \\
\hline
\end{tabular}

Then we pick up $f=15 \mathrm{kHz}$ for the system so that we get $R_{1}, R_{2}, C_{2}$, and $Z_{\mathrm{L}}$ as shown in the right column of Table $\mathrm{I}$. Next step, we use the parameters from Table I to compute an optimal $C_{l}$ which is $2.7969 \mathrm{uF}$ using (2).

Then, we use $C_{l}$ and the parameters to find $M$ using (5), i.e. $M=2.6697 \mu \mathrm{H}$. Finally, we calculate $\eta=55.265 \%$ using (14). The equivalent circuit for a simulation can be shown in Fig. 4. 
INTERNATIONAL JOURNAL OF INNOVATIVE RESEARCH IN ELECTRICAL, ELECTRONICS, INSTRUMENTATION AND CONTROL ENGINEERING Vol. 4, Issue 1, January 2016

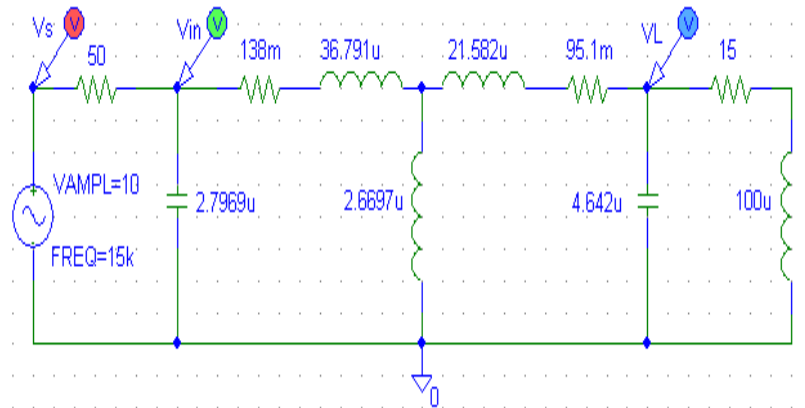

Fig. 4. Pspice simulation of the PR structure, we set $V_{s}=$ $10 \mathrm{~V}$ at $f_{\mathrm{s}}=15 \mathrm{kHz}$. Connecting $Z_{L}=15+j \omega 100 \mu \Omega$. As a result, $\eta=55.2 \%$.

An experiment is conducted and set up according to parameters and an equivalent circuit in Fig. 4, which is illustrated in Fig. 5. From Fig. 5, we obtain the transfer distance; $d$ as $8 \mathrm{~cm}$ from (17) by a for-loop

$$
M=\mathrm{N}_{1} \mathrm{~N}_{2} \mu_{0} \sqrt{\mathrm{a}_{1} \mathrm{a}_{2}}\left[\left(\frac{2}{k}-k\right) K(k)-\frac{2}{k} E(k)\right]
$$

In which, $K(k)$ and $E(k)$ are the first and second kind of elliptic integrations as shown in (18) and (19), respectively, they are solved by numerical integration [13].

$$
\begin{aligned}
& K(k)=\int_{0}^{\frac{\pi}{2}} \frac{d \theta}{\sqrt{1-k^{2} \sin ^{2} \theta}} \\
& E(k)=\int_{0}^{\frac{\pi}{2}} \sqrt{1-k^{2} \sin ^{2} \theta} d \theta
\end{aligned}
$$

Where,

$$
k=\sqrt{\frac{4 \mathrm{a}_{1} \mathrm{a}_{2}}{\left(\mathrm{a}_{1}+\mathrm{a}_{2}\right)^{2}+d^{2}}}
$$

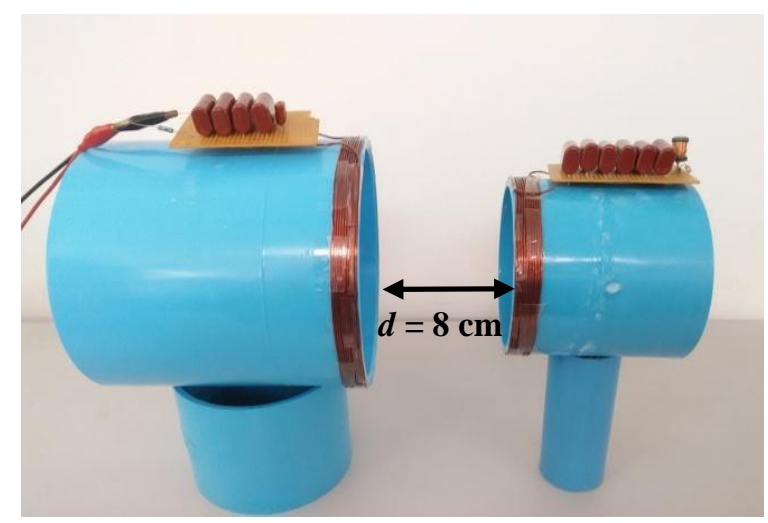

Fig. 5. Experiment setup for the PR structure. $a_{1}=9 \mathrm{~cm}$ and $\mathrm{a}_{2}=6.2 \mathrm{~cm}$, they have $\mathrm{N}=10$ turns, $\mathrm{b}=0.5 \mathrm{~mm}, \mathrm{p}=$ $1.1 \mathrm{~mm}, \mathrm{~h}=12 \mathrm{~mm}$. Connecting $C_{l} \approx 2.7 \mu \mathrm{F}, C_{2} \approx 4.5 \mu \mathrm{F}$, $R_{s}=50 \Omega$, and $Z_{L}=15+j \omega 100 \mu \Omega$. As a result, $d=8 \mathrm{~cm}$, and $\eta=48.87 \%$.

\section{RESULTS}

The results of the simulation and the experiment can be obtained and shown in Fig. 6.

From Fig. 6, according to IM condition, $V_{\text {in }}$ of the simulation and the experiment are half of $V_{s}$. The efficiencies of both can be compared as shown in Table II.

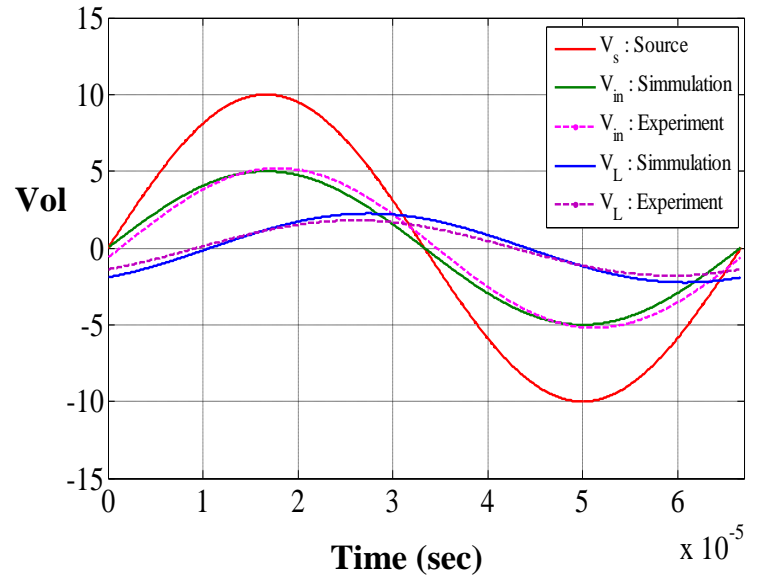

Fig. 6. The measured $V_{s}, V_{i n}$, and $V_{L}$ in the simulations and the experiment.

TABLE II: THE VOLTAGE SIGNALS AND THE EFFICIENCIES

\begin{tabular}{cccc}
\hline \hline$V_{S}=10 \mathrm{~V}$ & $V_{\text {in }}(\mathrm{V})$ & $V_{L}(\mathrm{~V})$ & $\eta(\%)$ \\
\hline & & & \\
Simulation & $5 \angle 0^{\circ}$ & $2.247 \angle-58.24^{\circ}$ & 55.2 \\
Experiment & $5.2 \angle-7^{\circ}$ & $1.8 \angle-50.624^{\circ}$ & 48.87 \\
\hline
\end{tabular}

Furthermore, the system is conducted by reducing the frequency from $30 \mathrm{kHz}$ to $10 \mathrm{kHz}$ with a stage of $1 \mathrm{kHz}$ with the same process of setting the parameters as presented above. The efficiencies of the simulations and the experiment can be shown as in Fig. 7.

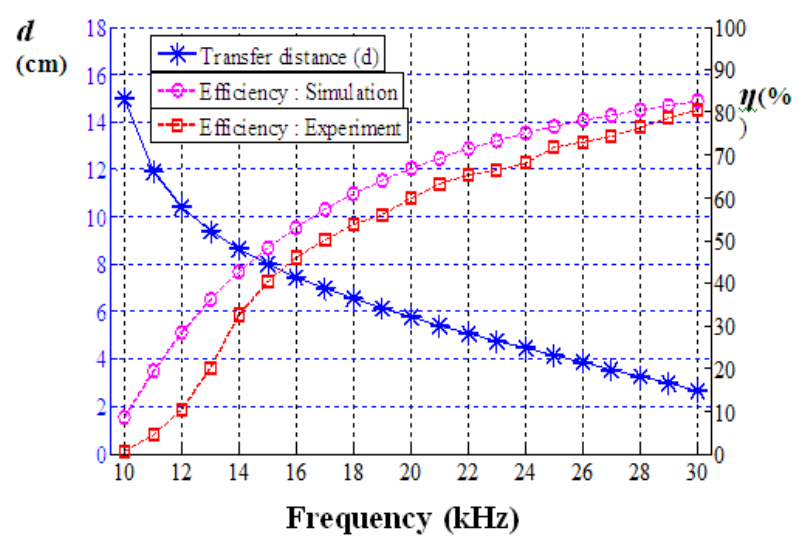

Fig. 7. Increasing the transfer distance by reducing the frequency while maintaining the IM condition.

From Fig. 7, by reducing the frequency, we can also increase the transfer distance while maintaining the IM condition, which is different from the previous the twocoil SR, since the transfer distance can be increased by increasing $f_{0}$ while maintaining the IM condition [10], [13]. The efficiencies, $\eta$, of the simulations and the experiments are not same due to various reasons as follows: 1) Leakage inductance of the coils [10]. 2) Parasitic losses of the devices and the circuit.

\section{CONCLUSION}

Most of the researches in WPT field have proposed the series resonant structures at the frequency $f_{0}$ in a range 200 
$\mathrm{kHz}-13.56 \mathrm{MHz}$ using air-core coils with a resistive load. But the high frequency causes several problems and the SR structures are difficult to be designed for a complex load under the IM condition. Thus, a WPT requires for a low frequency operation at the complex load (common loads are complex).

In this paper, we propose the method to design the parallel resonant structure, which can operate at a low frequency of $15 \mathrm{kHz}$ with a lagging load under the IM condition. For future work, we can use ferrite core instead of using aircore coils, so that we can reduce the frequency being less than $1 \mathrm{kHz}$ and increase the efficiency being greater than $60 \%$ while maintaining the high efficiency.

\section{ACKNOWLEDGMENT}

This work was supported financially by the Higher Education Research Promotion and National Research University Project of Thailand, Office of the Higher Education Commission. The authors would like to thank the Quantum based Engineering and Signal Processing Research Group, Faculty of Engineering, Thammasat University, for technical supports.

\section{REFERENCES}

11] Yiming Zhang, Zhengming Zhao, and Kainan Chen, "Frequency Decrease Analysis of Resonant Wireless Power Transfer," IEEE Trans. Power Electronics, vol. 29, no. 3, pp. 1058-1063, March 2014

[2] Alexey Bodrov, Seung-Ki Sul (2012), “Analysis of Wireless Power Transfer by Coupled Mode Theory (CMT) and Practical Considerations to Increase Power Transfer Efficiency," Wireless Power Transfer - Principles and Engineering Explorations, Dr. Ki Young Kim (Ed.), ISBN: 978-953-307-874-8, InTech.

[3] Takehiro Imura, Yoichi Hori, "Maximizing Air Gap and Efficiency of Magnetic Resonant Coupling for Wireless Power Transfer Using Equivalent Circuit and Neumann Formula," IEEE Trans. Industrial Electronics, vol. 58, no. 10, July 2011

4] Erin M. Thomas, Member, Jason D. Heebl, Carl Pfeiffer, and Anthony Grbic, "A Power Link Study of Wireless Non-Radiative Power Transfer Systems Using Resonant Shielded Loops," IEEE Trans. Circuits and Systems-I: Regular Papers, vol. 59, no. 9, September 2012.

[5] S. Y. R. Hui, Wenxing Zhong, and C. K. Lee, "A Critical Review of Recent Progress in Mid-Range Wireless Power Transfer," IEEE Trans. Power Electronics, vol. 29, no. 9, September 2014.

[6] Runhong Huang, Bo Zhang, "Frequency, Impedance Characteristics and HF Converters of Two-Coil and Four-Coil Wireless Power Transfer," IEEE Journal of Emerging and selected topics in Power Electronics, vol. 3, no. 1, March 2015.

[7] Kim Ean Koh, Teck Chuan Beh, Takehiro Imura, Yoichi Hori, "Impedance Matching and Power Division Using Impedance Inverter for Wireless Power Transfer via Magnetic Resonant Coupling," IEEE Trans. Industry Applications, vol. 50, no. 3, May/June 2014

[8] Siqi Li, Chunting Chris Mi, "Wireless Power Transfer for Electric Vehicle Applications," IEEE Journal of Emerging and selected topics in Power Electronics, vol. 3, no. 1, March 2015.

9] Anil Kumar RamRakhyani, Shahriar Mirabbasi, Mu Chiao, "Design and Optimization of Resonance-Based Efficient Wireless Power Delivery Systems for Biomedical Implants," IEEE Trans. Biomedical Circuits and Systems, vol. 5, no. 1, February 2011.

[10] Marco Dionigi, Alessandra Costanzo, Mauro Mongiardo (2012), "Network Methods for Analysis and Design of Resonant Wireless Power Transfer Systems," Wireless Power Transfer - Principles and Engineering Explorations, Dr. Ki Young Kim (Ed.), ISBN: 978953-307-874-8, InTech

[11] Yiming Zhang, Zhengming Zhao, "Frequency Splitting Analysis of Two-Coil Resonant Wireless Power Transfer," IEEE Trans. Antennas and Wireless Propagation Letters, vol. 13, pp. 400-402, 2014.
12] Meysam Zargham and P. Glenn Gulak, "Maximum Achievable Efficiency in Near-Field Coupled Power-Transfer Systems," IEEE Trans. Biomedical Circuits and Systems, vol. 6, no. 3, June 2012.

13] A. Rittiplang, W. Pijitrojana, "A Low Frequency Wireless Power Transfer Using Parallel Resonance under Impedance Matching", Applied Mechanics and Materials, Vol. 781, pp. 410-413, Aug. 2015

[14] Hao Jiang, Junmin Zhang, Di Lan, Chao K.K, Shyshenq Liou, Shahnasser, H, Fechter, R, Hirose, S, Harrison M, Roy S, "A LowFrequency Versatile Wireless Power Transfer Technology for Biomedical Implants," IEEE Trans. Biomedical Circuits and Systems, vol. 7, no. 4, pp. 526 - 535, Aug. 2013.

[15] Lin J.C, "Wireless Power Transfer for Mobile Applications, and Health Effects [Telecommunications Health and Safety]," IEEE, Antennas and Propagation Magazine, vol. 55, no. 2, pp. 250 - 253, April 2013.

[16] Muhammad Taha Ali, Ali Anwar, Umais Tayyab, Yasir Iqbal, Tauseef Tauqeer, Usman Nasir, "Design of High Efficiency Wireless Power Transmission System at Low Resonant Frequency," 16th International Power Electronics and Motion Control Conference and Exposition, Antalya, Turkey 21-24 Sept 2014

[17] Ada S. Y. Poon, Stephen O’Driscoll and Teresa H. Meng, “Optimal Frequency for Wireless Power Transmission into Dispersive Tissue," IEEE Trans. Antennas and Propagation, vol. 58, no. 5, pp. 1739-1750, May 2010.

[18] S. Chopra, P. Bauer, "Analysis and Design Considerations for a Contactless Power Transfer System," Telecommunications Energy Conference (INTELEC), 2011 IEEE 33rd International, Amsterdam.

[19] Trevor S. Bird, Nicholas Rypkema, and Ken W. Smart, “Antenna Impedance Matching for Maximum Power Transfer in Wireless Sensor Networks," Sensors, 2009 IEEE, pp. 916 - 919, 25-28 Oct 2009. 